\title{
SPECIFICATION MODEL FOR THE DEVELOPMENT AND OPERATION OF A VIRTUAL COMPANY IN THE AEROSPACE INDUSTRY
}

\author{
Barbara Odenthal \\ Chair and Institute of Industrial Engineering and Ergonomics (IAW) \\ at University of Technology Aachen (RWTH Aachen University) \\ e-mail:B.Odenthal@iaw.rwth-aachen.de
}

Meikel Peters

Chair and Institute of Industrial Engineering and Ergonomics (IAW) at University of Technology Aachen (RWTH Aachen University) e-mail: M.Peters@iaw.rwth-aachen.de

\begin{abstract}
The reorganization of the supply chain in the aerospace industry has led to a new situation for small and medium-sized enterprises (SME). The suppliers are forced to deliver completed systems instead of components and assemblies. In order to react to the changed requirements, one possible solution is the project-oriented and temporary cooperation of SME by building a Virtual Organization in order to stay competitive and marketable. The research project AerViCo - Aerospace Virtual Company - is aimed at developing standard business processes, structures and tools to support a Virtual Organization in the aerospace industry.
\end{abstract}

\section{INTRODUCTION}

During the past years the development of the corporate strategy of manufacturers in the aerospace industry has led to a new situation for small and medium-sized enterprises (SME). In order to lower their costs, European consolidated companies in the aerospace industry (Airbus, EADS, astrium, Lagardere, ...) have re-organized their supplier network. The large number of direct suppliers caused enormous expenses regarding the coordination, the quality control and the auditing of the suppliers. By reducing the number of direct suppliers from several hundred to less than 10 strategic suppliers, the large enterprises expect not only better planning and control of their costs, an increase in output and a better quality of their products but also a decrease in their administrative work. In the long run, internationally operating enterprises are planning to reduce the number of strategic suppliers in all participating countries. Thus, one of the main requirements of aircraft manufacturers towards their strategic suppliers is an increasing international orientation. Furthermore, these strategic suppliers which have to be audited and certified are commissioned to deliver completed systems instead of components and assemblies. 
In addition to the order processing, the first level suppliers are now also responsible for the monitoring and the compliance of second and third level suppliers with the quality standards. Consequently the above mentioned requirements are handed on to the second and the third level suppliers which are mainly SME. In order to respond to the new situation, one possible solution is the creation of a virtual network of SME which join forces in the case of an order processing flexibly adjusting to the requirements at hand (Peters/Bernhard, 2004). The cooperation within virtual companies on the other hand presents SME with new challenges concerning the work organization, the division of labor and the support by tools and methods in flexible networks.

To support SME with the development and operation of such virtual networks and to make the concept of virtual companies accessible to SME of the aerospace industry a research project - AerViCo - Aerospace Virtual Company - was initiated. The objective of the project is to develop a cooperation network of SME which is the basis for forming project consortiums to process a certain order. To do so, standard business processes, structures and tools to support a Virtual Company in the aerospace industry will be developed.

As one of the first achievements of the project, a specification model for Virtual Companies which meets the special requirements of SME in the aerospace industry was developed. Initially the model was set up literature based and provided a structure for a series of interviews with experts from the considered industry. The interview results were used to verify and further detail the model concerning the practical requirements of the aerospace industry.

\section{SPECIFICATION MODEL FOR VIRTUAL COMPANIES}

As a basis for the development and operation of Virtual Companies a specification model was developed based on a literature research (Albers et al., 2003) (Gerpott et al., 2000) (Kocian, 1999) (Ries, 2001) (Ringle, 2004) (Schuh et al., 2003) (Katzy, 1998) (Reid et al., 1996) (Camarinha-Matos, 2003) (Tølle, 2003). The model allows the description of all the relevant design areas of a Virtual Company in the aerospace industry which are namely (see figure 1):

- the core processes for building the cooperation platform and for the realization of concrete projects

- the supporting processes for administration and marketing of the network as well as project controlling and quality management

- in addition to the process level the IT-support plays an essential role in order processing in a distributed context

- finally the employee level must be considered carefully when designing Virtual Networks since especially in knowledge intensive networks the effective cooperation between employees is a success factor. 


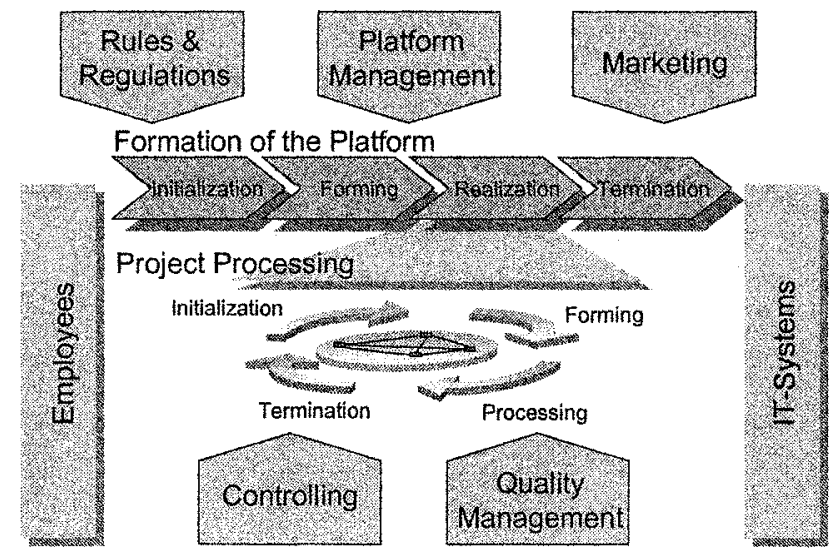

Figure 1: Specification Model for Virtual Companies in the Aerospace Industry

\subsection{Core Processes and Supporting Tasks}

The specification model for Virtual Companies was developed based on the phases of cooperation (Killich/Luczak, 2003). Regarding these phases of cooperation in Virtual Companies two levels can be distinguished: the platform level and the project level. On platform level the initialization, forming, realization and termination of the cooperation platform - the loose cooperation between potential project partners - are described. The phase of initialization starts with identifying potentials for a cooperation platform and defining goals of cooperation. The main tasks of the forming phase are the selection and assessment of potential network partners and the following negotiation with these. In the realization phase the cooperation platform carries out its original purpose, namely, the flexible configuration of project networks in order to achieve customer oriented order processing while concentrating on the network partners' core competencies. Finally, the termination of such a cooperation platform is possible. In this case the reasons for termination must be identified, collective resources must be divided and perhaps lessons learnt for future cooperations are generated.

The project level - the processing of concrete orders through flexible project networks - can also be described using four rather similar phases. A project starts with the identification of a market chance or an order by a customer in the initialization phase. According to the requirements of the market chance or the order, the project is defined, structured and planned in the phase of formation. A project network is configured considering the competencies required for the order processing and the existing core competencies of the members of the cooperation platform. The following phase of order processing mainly consists of the direct processes of the network partners and the project management for distributed projects. Finally the project network will be terminated, in most cases because the project goals were fulfilled. In consequence of the project, there might be further project related tasks, e.g. after sales services, that are carried out by one or several project partners. 
The processes and tasks described so far are the direct processes on platform as well as on project level. In addition to these, supporting processes are necessary to ensure an effective and efficient cooperation based on the cooperation platform.

A number of problems often inhibit efficient collaboration in interorganizational networks. As a matter of fact, different goals and ethic values among the network partners as well as dynamic changes of processes are very complex to handle (Killich/Luczak, 2003). The higher the flexibility of the network, the more important the aspect of trust becomes, as it can no longer be built on extensive experience with the partners. Yet another major challenge is the overcoming of barriers due to different organizational cultures of network partners (Eppler/Sukowski, 2001).

The cooperation platform plays a main role in reducing these barriers. It provides a stable and long term pool of potential partners, supports the development of trust among partners and provides a certain degree of standardization to ensure efficient cooperative processes. To fulfil these requirements the cooperation platform must provide rules and regulations for the general cooperation between partners on platform level as well as on project level. The supporting processes also include the various tasks of platform management, e.g. finding new network partners, excluding partners from the network, measures of trust building and conflict management and also the development and operation of an adequate IT-infrastructure. Since one of the general characteristics of a Virtual Company is the collective market appearance of the network companies, the marketing of the cooperation platform is also an essential task on this level. These supportive and administrative tasks are usually carried out by the broker of the network.

Further, supporting processes that are important on platform level as well as on project level can be distinguished: controlling of all the activities of the platform is necessary to ensure the compliance with the goals of the platform and if necessary implement corrective measures. The different processes of quality management are particularly important since the aerospace industry strongly focuses on high quality standards.

\subsection{IT-Support for Virtual Companies}

Because of the collaboration in a distributed environment, an adequate IT-support of the processes of a Virtual Company is essential (Katzy et al., 2004) (DeSanctis/Monge, 1999) (Cohen/Mankin, 1999). The specification of the ITsupport of a Virtual Company can be structured according to the life cycle as described above and the functions that are supported (see figure 2), namely information, communication, collaboration and coordination (Mertens, 1998). The initialization phase mainly requires support regarding informational functions, e.g. for identifying potentials for cooperation. These tasks can be supported for example by web-based databases or by electronic yellow pages. During the phase of formation communication systems - e.g. email, chat, ICQ, telephone and video conference, blackboard, news - gain importance in addition to information systems. In the following phase of realization the focus lies on the support of the operative project work by systems for collaboration and coordination. Examples for these are groupware document and Knowledge Management systems, newsgroups, Workflow Management Systems, Project Management Systems and Supply Chain 
Management systems. The phase of termination finally requires support by systems providing mainly informational functions.

The main challenge, however, lies within finding adequate IT-support for the cooperative work that can be efficiently integrated into the existing operative systems of the network partners.

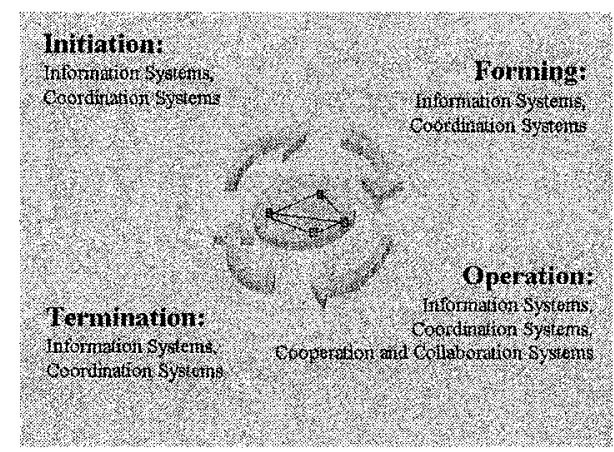

Figure 2: Description of the phases and of the corresponding IT systems (Mertens, 1998)

\subsection{Employee-Related Aspects of Virtual Companies}

As already mentioned interorganizational cooperation is always based on the actions of human beings. In a virtual context certain requirements towards employees are intensified and therefore should be considered carefully. In particular in knowledgeintensive cooperations the success depends on the efficient interaction of employees to a large extent. Because of this, the processes, structures and related tasks as well as supportive tools and instruments must be designed considering the effects on employee performance behavior.

In order to ensure compliance of employee behavior with the Virtual Companies' goals three aspects are of importance (Killich/Peters, 2003): commitment ("Are employees willing to act in a certain way?"), capability ("Are employees able to act in that way?") and conditions ("Do organizational and cultural conditions enable this kind of behavior?").

Regarding the area of commitment, structures, processes, areas of responsibility, decision authority should be reflected under motivational aspects.

The area of capability takes into account whether employees have adequate competencies to carry out the required tasks. This question is of particular interest since in a networked context social competencies, language and communication skills are needed in addition to excellent professional competencies.

With the third area, conditions, the view is extended to the surroundings of the employees. In this context for example aspects of organizational culture and trust between members of a virtual environment play an important role. 


\section{REQUIREMENTS OF THE AEROSPACE INDUSTRY TOWARDS A VIRTUAL COMPANY}

The specification model provided a theoretical framework which had to be adapted to the particular requirements of a Virtual Company in the aerospace industry. Therefore, a series of interviews with involved companies from different levels of the supply chain (producer, 1st-tier supplier, 2nd-tier supplier and 3rd-tier supplier) was conducted.

In order to be able to cover the demands of SME towards the design of a cooperation platform, several potential network partners were questioned about their previous cooperations and the reasons for these. Furthermore, a particular focus lay on the prearrangements of the cooperation in respect to the selection and the rating of the potential partners and the contractual agreements. Finally, the order processing was analyzed regarding the role of the IT systems, the role of the employees and the contractual agreements during the cooperation.

The main reasons for cooperation given in the survey were the expansion of the product range and of the core competencies. Most of the companies announced that reciprocal specialization as well as know-how and knowledge transfer is highly important. All interviewees stated the long-term orientation of their past cooperations. Nearly all cooperations took place without a specific legal form but mainly on the basis of customer-supplier relationships.

Regarding the organization of the network respectively the cooperation platform, it appeared that the companies join forces in the case of a concrete project depending on the requirements at hand, so that the platform is often not managed explicitly. According to the questioned companies the important processes on platform level are the definition of corporate aims and merits, the fixing of rules and regulations, the strategy for the corporate marketing which must strictly market the product range of the cooperation platform and the integration of existing as well as the development of a new consistent IT structure.

In the case of an order processing, the following aspects are important for successful operating: finding the most promising combination of the partner companies, the clear structuring of the project and the definition of work packages, quality management and controlling supported by specialized IT systems and methods.

Because of the high quality standards of the considered industry, aspects of quality management must be integrated explicitly into the structures and processes of an Aerospace Virtual Company. The most important standards are the following:

- DIN EN ISO 9001: Quality Management Systems

- DIN EN 9100: Quality Management Systems in the Aerospace Industry

- ISO/TR 17400: Space systems - Space launch complexes, integration sites and other facilities - General testing guidelines

- JAR 21: Certification Procedures for Aircraft and related Products and Parts

As a result of the customer requirements and because of the conceptual formulation, most of the used IT tools are predetermined. In this regard, a secure well-structured electronic data interchange is one of the most important aspects concerning the configuration of a Virtual Company. 
Because of the common customer request of being informed about each network partner involved in the order processing, the aim of the collective marketing cannot always be reached. Regarding the different roles in an Aerospace Virtual Company there is usually a prime-contractor who closes the deal with the customer. In order to fix the decisions and the work packages contractually, the prime-contractor is responsible for the arrangements with the cooperating companies.

In the context of working within a trans-national Virtual Company, the analysis of the interview results lead to the conclusion that the increasing importance of the role of the employees must be taken into consideration. The interviewees stated the increasing requirements regarding professional competencies as well as language skills, the flexibility concerning different fields of work and social competencies among other things due to the increasing international cooperation in the aerospace industry.

\section{DISCUSSION AND OUTLOOK}

To provide a basis for the specification of a Virtual Company in the aerospace industry a model describing all the relevant design areas was presented.

The model was detailed regarding the special requirements of the aerospace industry through a series of interviews with small and medium enterprises that have experiences with cooperative work in the respective industry. In order to also collect the requirements of potential customers of an Aerospace Virtual Company further interviews were carried out with aircraft manufacturers and their direct suppliers.

The next step in the project will be the development of concepts, IT-Tools, methodological support and framework agreements for the development and operation of a Virtual Company in aerospace industry according to the specification model. Accompanying the conceptual work the acquisition of a concrete evaluation project will be worked on by the project consortium. This project will be used to configure a Virtual Company according to the developed concepts and to apply and evaluate the supporting tools and methods.

As a result a complete and validated guideline for the development and operation of an Aerospace Virtual Company for small and medium enterprises will be provided.

\section{ACKNOWLEDGMENTS}

The Project „AerViCo - Aerospace Virtual Company" is funded by the German Federal Ministry of Education and Research (grant number: 01HU0160 01HU0169). The other partners are: AIDA Development GmbH, Schwaebisch Hall, ALROUND e.V., Bonn, ANSYS Germany GmbH, Otterfing, Fraunhofer - Institut für Materialfluss und Logistik (IML), Dortmund, HEGGEMANN Aerospace AG, Büren, HTS GmbH, Coswig, IMA Materialforschung und Anwendungstechnik $\mathrm{GmbH}$, Dresden, MST Aerospace GmbH, Köln, ProTec-Recycling, Werne. 


\section{REFERENCES}

1. Albers, S., Bisping, D., Teichmann, K., Wolf, J.: Management Virtueller Unternehmen. Wiesbaden: Albers, S., Wolf, J. (eds.), Deutscher Universitäts-Verlag GmbH, 2003.

2. Camarinha-Matos, L., Afsarmanesh, M.H., Raselo, R.J.: Infrastructure developments for agile virtual enterprises, in: Int. Journal of Computer Integrated Manufacturing, 16, 2003, No. 4-5.

3. Cohen, S.G., Mankin, D.: Collaboration in the Virtual Organization, in: Cooper, C. L.; Rousseau, D. M. (eds.): Trends in Organizational Behavior, Vol. 6, Chichester, 1999, 105-120.

4. DeSanctis, G., Monge, P.: Introduction to the special issue: Communication processes for virtual organizations, in: Organization Science, 10, No. 6, 1999, 693 - 703.

5. Eppler, M.J., Sukowski, O. (eds.): Fallstudien zum Wissensmanagement: Lösungen aus der Praxis. St. Gallen: NetAcademy Press, 2001.

6. Gerpott, T. J., Böhm, S.: Strategisches Management in virtuellen Unternehmen, in: Albach, H. (ed.): Virtuelle Unternehmen, ZfB-Ergänzungsheft 2/2000, Wiesbaden, $13-35$

7. Katzy, B. R., Sung, G., Serrano, C.: Managing virtual projects - A benchmark study of collaboration tools, 2004. Internet source: http://www.ve-forum.org/, date: 17.12.2004.

8. Katzy, B. R.: Design and Implementation of Virtual Organizations, Proceedings of the 31 st Hawaii International Conference on System Sciences, Maui, 1998.

9. Killich, S., Luczak, H.: Unternehmenskooperation für kleine und mittelständische Unternehmen. Berlin: Springer, 2003.

10. Killich, S., Peters, M.: The Interest of employees in Knowledge Sharing: A Theoretical Framework for the Integration of Motivation, Qualification and Organization for Knowledge Management in Networks. In: Luczak, H. ; Zink, K.J. (eds.): Human Factors in Organizational Design and Management - VII. Proceedings of the Seventh International Symposium on Human Factors in Organizational Design and Management held in Aachen, October 1-2, IEA Press, Santa Monica, CA, USA 2003, 373-378.

11. Kocian, C.: Virtuelle Kooperationen im Mittelstand, Wiesbaden, 1999.

12. Mertens, P.: Virtuelle Unternehmen und Informationsverarbeitung, Berlin: Springer, 1998.

13. Peters, M., Bernhard, J.: Virtuelle Zulieferkooperationen in der Luftfahrtindustrie - Entwicklung eines Konzeptes zum Aufbau und Betrieb Virtueller Unternehmen unter Berücksichtigung organisatorischer, technischer und personeller Faktoren. In: Unternehmen der Zukunft, Aachen, 5, 2004,$4 ; 3-4$.

14. Reid, R. L., Rogers, K. J., Johnson, M., Liles, D.: Engineering the Virtual Enterprise. Fifth Industrial Engineering Research Conference. Minneapolis, Minnesota, 1996, 485 - 490.

15. Reinhardt, G., Mehler, B.: Organisatorische und informationstechnische Aspekte beim Aufbau virtueller Fabriken. In: Kaluza, B./Blecker, T. (eds.): Produktions- und Logistikmanagement in Virtuellen Unternehmen und Unternehmensnetzwerken, Heidelberg, 2000, S. 391-420.

16. Ries, A.: Controlling in virtuellen Netzwerken, Wiesbaden, 2001.

17. Ringle, C. M.: Die Virtuelle Unternehmung. Ausprăgungsformen und Abgrenzung, in: Der Betriebswirt, 45, No. 2, 2004, $21-29$.

18. Schuh, G., Kurr, M., Friedli, T.: Das Konzept „Virtuelle Fabrik“ - Aufbau, Betrieb und Auflösung. In: Bullinger, H.-J.; Warnecke, J.; Westkämper, E. (eds.): Neue Organisationsformen im Unternehmen - Ein Handbuch für das moderne Management, 2nd ed., Berlin, 2003, 627 - 643.

19. Schuh, G., Millarg, K., Göransson, A.: Virtuelle Fabrik, Munich, 1998.

20. Tølle, M.: Reference models supporting enterprise networks and virtual enterprises, in: Int. J. Networking and Virtual Organisations, 2, 2003, No. 1, 2-15. 